\title{
Numerical Investigation on the Effect of Inflow Mach Numbers on the Combustion Characteristics of a Typical Cavity-Based Supersonic Combustor
}

\author{
Namrata Bordoloi ${ }^{D}$, Krishna Murari Pandey ${ }^{(D)}$, and Kaushal Kumar Sharma \\ Department of Mechanical Engineering, National Institute of Technology, Silchar, India \\ Correspondence should be addressed to Krishna Murari Pandey; kmpandey2001@yahoo.com
}

Received 21 April 2021; Revised 5 August 2021; Accepted 28 August 2021; Published 9 September 2021

Academic Editor: Zhengbiao Peng

Copyright (c) 2021 Namrata Bordoloi et al. This is an open access article distributed under the Creative Commons Attribution License, which permits unrestricted use, distribution, and reproduction in any medium, provided the original work is properly cited.

\begin{abstract}
The air-breathing engines, commonly known as Supersonic Combustor Ramjet (SCRAMJET) engines, are one of the most prominent technologies among researchers due to their high thrust-to-weight ratio. The researchers are constantly making efforts for improved performance of the combustor under the required boundary conditions. The present working computational model studies a hydrogen-fueled parallel cavity scramjet combustor to recognize the complex flow field characteristics and performance of the combustor in Ansys 15.0. The computational model developed is a replica of an experiment conducted in China which slightly modified the boundary conditions. The standard two-equation K- $\varepsilon$ turbulence model and Reynolds averaged Navier Stokes (RANS) equation with finite-rate/eddy dissipation species reaction model are used to simulate the problem. The validation of the present model is achieved by comparing the results with already available experimental data in conformity with the literature. The results of the simulations are in satisfactory accord with the experimental data and images. Furthermore, to achieve the stated objective, different incoming Mach numbers, namely, 2.25, 2.52, and 2.75, are considered for a more clear understanding of variables that affects the characteristics of the flow field. The temperature, Mach number, density pressure, and $\mathrm{H}_{2} \mathrm{O}$ mass fraction contours were studied to facilitate proper understanding. The maximum temperature rise observed is $2711.467 \mathrm{~K}$ for $M=2.25$. Additionally, the performance parameters, namely, combustion and mixing efficiencies, are also studied. The maximum combustion and mixing efficiencies are $87.47 \%$ and $98.15 \%$ for $M=2.25$ and 2.75 , respectively.
\end{abstract}

\section{Introduction}

Supersonic combustion ramjet, also known as Scramjet engines, is nowadays one of the prominent developing technologies of the hypersonic industry. The scramjets are a development of ramjet engines where the combustion process occurs at supersonic speeds, unlike ramjets where the combustion occurs at subsonic speeds. In the $21^{\text {st }}$ century era, the desire for reusable launch vehicles in many space programs has been seen. The scramjets have the potential to sustain at hypersonic speed with a proper carrier vehicle to take it to hypersonic speed. In several space programs, such as the X51A, which was successfully tested by NASA, the flight lasted for 200 secs at incoming Mach 5 [1,2]. Similarly, the Indian Space Research Organization (ISRO) assessed a scramjet engine in the year 2016. The flight lasted for 5 secs for Mach 6 [3-5].

The scramjet engines use the physics of any jet propulsion engine, namely Turbojets, Ramjets, Scramjet, etc. Jet propulsion works at high velocities. These engines exhaust hot gases resulting from the combustion and create the required thrust to move forward at high velocities. The turbojet engines consist of a compressor, combustor, turbine, and nozzle. Additionally, turbofan engines have a fan that sucks the air that is to be compressed. However, modern jet engines such as pulsejet, ramjet, and Scramjet do not have a compressor and turbine [3]. The ramjet engine uses a high forward motion speed to compress the air. But, the efficiency starts to lower when it reaches hypersonic velocities. The scramjet engine is a modification of the ramjet engines with 
the motive to improve its performance at high velocities. The Scramjet engines, unlike any other jet engines, have simple geometry without any moving parts. It allows the air to enter the inlet at supersonic speed. Since it has no moving parts, it uses the atmospheric oxygen for the combustion to occur at supersonic conditions [6-8]. One of the prime challenges in supersonic technology is the proper designing of the combustion chamber, which is the most crucial part of the engine [4-6]. The combustion process is concluded within milliseconds due to its supersonic velocity. It is also seen that there is inadequate burning of fuel and air. Additionally, very little time is available for atomization, ignition, and vaporization, and improper combustion occurs, which causes wastage of fuel. The complexities of the supersonic combustor result in intense unsteadiness in the combustor [7]. The process of combustion is initiated by the formation of the subsonic regions that originated from the holders. The subsonic regions result in the propagation of acoustic waves that infect the mixing process [8-10]. These pressure waves induce instabilities in the combustion process. The rise in pressure in the combustor induces the formation of a shock train. Due to which there is a change in the reacting conditions. To overcome the unsteadiness, acoustic vibration modes can be implemented in the combustor.

\subsection{Challenges in the Design of Scramjet Engines. To address} this challenge, proper designing of the combustion chamber by implementing an appropriate fuel injection/ flame holding approach into the combustor is necessary. Inside the scramjet combustor, the introduction of different flame holding mechanisms and different ignition mechanisms has been investigated by researchers in terms of various fuel injection mechanisms and different cavity and strut-based flame holders [11-13] are found in the literature. The performance of the scramjet engines is substantially affected by the flame holder and fuel injection location. In the literature, many studies have been found that dictate the enhancement of performance of the Scramjet combustor with different flame holders and fuel injection mechanisms. Some of the studies are discussed in this paper.

Tian et al. [14] investigated the effect of injector position and ER on a hydrogen-fueled scramjet combustor with incoming Mach number 2.0 experimentally. From the experimental results, it was identified that for ER-1.0, back pressure was developed (due to combustion), which did not spread to the isolator. However, the backpressure was observed to spread to the isolator for ER-3.0. Also, regarding the injector location, it was seen that fuel-injected upstream burnt efficiently than the downstream injectors.

Wang et al. [15] experimented with a cavity flame holder scramjet combustor with the motive to understand the behavior of combustion. The flame appeared to move into the mainstream, provided the favorable conditions were available for the spreading. It was observed that the combustion started to spread from the shear layer. Hence, the appearance of cavity stabilized mode around the cavity is the appropriate process for heat release.
Liu et al. [16] investigated the cavity holding mechanism for Mach 4.5 on an optical axisymmetrical scramjet combustor. It was established that for different ER namely 0.65, 1.10 , and 1.55, the cavity acted as a flame holder for the combustor. Also, it was seen that above the cavity, the flame resided at the shear layer. The contours of Mach number show heat addition near the walls that help in achieving flame stabilization.

Huang and Yan [17] discussed the ram to scram mechanism on a strut-based combustor by varying the inlet boundary condition. The results of the numerical simulation show that the transition of ram to scram is influenced by the inlet boundary condition and pressure ratio. At location $x=25 \mathrm{~mm}$, (leading edge of the strut), the first thermal choking and the subsonic region appear. The combustor operates at ramjet mode at a low Mach number, and the scramjet model appears for high Mach numbers.

Gerlinger and Bruggemann [18] investigated the different injector geometries to understand the mixing performance on planer supersonic jets. The results of the study show the generation of strong shock waves due to the strut geometry in the combustor. Additionally, it was also identified that the lip height increases with an increase in the mixing layer thickness, but it does have a significant impact on the mixing efficiency. The compressibility effects are seen on the combustor due to the decay of the normal velocity.

Berglund and Fureby [19] developed a 3D model of the scramjet combustor to understand the combustion performance. The results show that the LES model show precisely predicts the flow field variation in the reacting and nonreacting flow. Thus, the LES model provides more precise results in a $3 \mathrm{D}$ model than any other turbulence model.

Kumaran and Babu [20] developed a 3D scramjet model to understand the impact of chemistry modeling on the performance of the combustor. In the study, high fuel consumption and high heat release were observed in the multistep chemistry kinematics. Due to high heat release, the combustion efficiency was found high. Also, the staged injection yielded performance in terms of fuel injection schemes.

Another challenge is the proper selection of injection fuel. Hydrocarbon fuels such as hydrogen, kerosene, methane, ethylene, etc., have immense potential in the future of Scramjet technology [21-23]. Among the stated hydrocarbon fuels, hydrogen fuel is the most favorable fuel for supersonic condition combustion due to certain characteristics such as high energy density and eco-friendly $[13,24,25]$. It also has combustion-friendly characteristics as it burns more rapidly, has a lower molecular weight, low ignition delay [26-28], and a high tendency for flame stability which is beneficial for efficient mixing that enhances the process of combustion.

Designing of a dual-mode scramjet combustor was done to interpret the combustion characteristics for flight and entrance Mach 4.3-5.4, respectively, in an experiment by Micka and Driscoll [29]. In the experiment, pure hydrogen and a blend of hydrogen and ethylene were used as fuel. The results indicate the presence of two combustion stabilization locations upstream for the model to be in ramjet mode. 
Milligan [30] attempted to understand the impact of different scramjet combustor configurations on the performance of the combustor. The scramjet combustors used in the study are namely tapered without step and back stepped combustor for flight Mach 3.0. The results of the study reveal that the tapered combustor showed better performance. But the backstepped strut reaches the stoichiometric fuel-air ratio.

Li et al. [31] studied the fuel distribution characteristics on kerosene-fueled scramjet combustor with a dual cavity to interpret the effect of ignition pressure for flight and entrance Mach numbers 5.5 and 2.5, respectively. The formation of the shear layer plays an important role in fuel distribution and engagement. On a further study on the ignition pressure, it was found that the ignition pressure rises with an increase in penetration height. Also, the pressure required in fuel engagement at the cavities increases with the increase in the mass flux of the fuel.

Manna et al. [32] computationally studied the different fuel injection methods to understand their impact on the combustor performance. The simulations were carried out using the eddy dissipation model with Lagrangian Particle tracking model (LPTM) methods. The computational simulation results show the presence of minute amount of kerosene and oxygen at the exit plane and combustor walls. The combustor with modified strut location showed more thrust and combustion efficiency in the case of reacting flow.

Zhong et al. [33] used ethylene as fuel to describe the scramjet combustor with parallel cavities experimentally. On studying the contours, the appearance of two bundles of asymmetric flames near the cavity was observed. Also, it was identified in the scramjet. Furthermore, at the shear layer and the recirculation zone, the stabilized flame was observed. However, high heat release was seen due to the formation of a recirculation zone in the ramjet mode. Thus performance in the ramjet model can be improved by increasing the rate of heat release.

Shi et al. [34] studied the mechanism of flame holding for kerosene-fueled cavity-based scramjet combustor both experimentally and computationally. The tandem cavity flame holder configuration achieves stabilized flame, unlike a single cavity. For $L / D=9$, the tandem cavity exhibits high combustion and mixing efficiency. Thus the tandem cavity flame holder shows better performance than the single cavity.

From the stated literature above, it can be spotted out that ample work on the use of strut and cavity in the scramjet combustor to improve the combustor performance has already been discussed. However, the effect on the complex flow field of the combustor for different incoming air stream Mach numbers has barely been discussed. The objective of the work is to understand the effect of incoming Mach number on the complex flow field characteristics on hydrogen-fueled parallel cavities scramjet combustor using the standard $\mathrm{K}-\varepsilon$ model turbulence model. Furthermore, the effect on the performance of the combustor is evaluated in terms of combustion and mixing efficiencies. The numerical model modeled in Ansys Fluent is validated with two earlier feasible experimental studies, which are in conformity with the literature.

\section{Formulation of the Geometry}

The mixing performance of the fuel and air in the scramjet combustor is greatly influenced by the shear layer formation. Implementation of cavity flame holders in the combustor is one of the proven techniques to produce a shear mixing layer in the combustor. In this paper, the computational model bears parallel cavities with the motive to create a shear layer that improves the mixing performance of the combustor. The computational geometry is developed in Ansys Fluent 15.0 [35], and the dimensions are taken from an experiment conducted by Yang et al. [36-39] at the National University of Defence, China. In the experiment, a nozzle of Mach 2.52 is used to connect the isolator to the combustor. The combustor was designed with parallel cavities placed at a distance of $40 \mathrm{~mm}$ with a cavity depth of $8 \mathrm{~mm}$ and an aft wall angle of $45^{\circ}$. Hydrogen fuel is injected through injectors at sonic speed with a jet diameter of $2 \mathrm{~mm}$. The detailed dimensions in $2 \mathrm{D}$ and isometric view of the geometry are given in Figures 1(a) and 1(b).

A 2-dimensional model is selected based on a low percentage of uncertainty and to reduce the computational time. The computational domain for the simulation is of length $300 \mathrm{~mm}$ and width of $40 \mathrm{~mm}$. Since the geometry is symmetrical, only the upper wall geometry is designed. The meshing operation for the geometry is generated with the ICEM-CFD. Structured meshing operating is selected for the geometry as it provides better control over the interior nodes. In the current model, the structured mesh is created near the injectors and near the walls for rigid prediction of the generation of shock waves and enhanced mixing. Eventually, structured meshes with 717900 elements (including the mirror images) are selected as the final mesh for the further stimulations of the $2 \mathrm{D}$ geometry, as shown in Figure 2.

\section{Numerical and Combustion Modeling}

3.1. Numerical Modeling. The flow governing equations plays an important role in the understanding of the internal flow characteristics of the combustor. The combustion phenomenon inside the combustor for reacting flow problems is greatly affected by the flow variables. The flow inside the scramjet combustor is complex and turbulent. Thus, the governing equations selected are defined as turbulent and compressible flow equations. A 2D computational design of the combustor is modeled to perform all the simulations using Ansys Fluent 15.0 code. The governing equations are defined as Reynolds Averaged Navier-Stokes equations (RANS) to understand the combustion conduct for a spectrum of operating conditions and geometries. The RANS helps in precisely determining the position of the shock waves and understanding their characteristics. The flow governing equations and the species governing equation are discussed in the following [40-43]. The computational model is estimated with the help of a density-based solver with a standard K- $\varepsilon$ model is used. The mixing reaction for hydrogen with air is addressed by using finite-rate/ eddy dissipation (volumetric reaction) with density taken as 


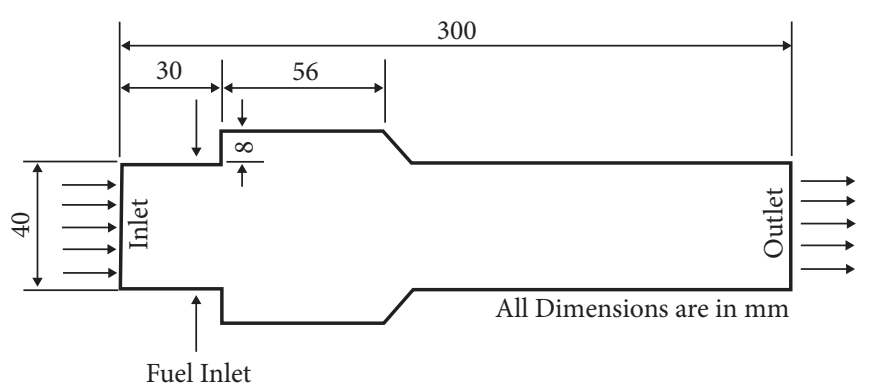

(a)

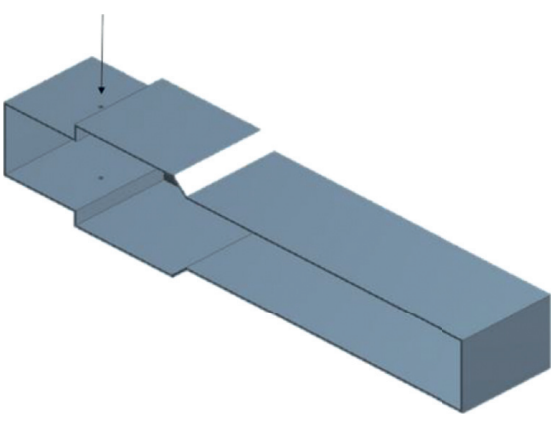

(b)

Figure 1: (a) Schematic diagram of the scramjet combustor (Yang et al. [36-38]). (b) Isometric view of the combustor.
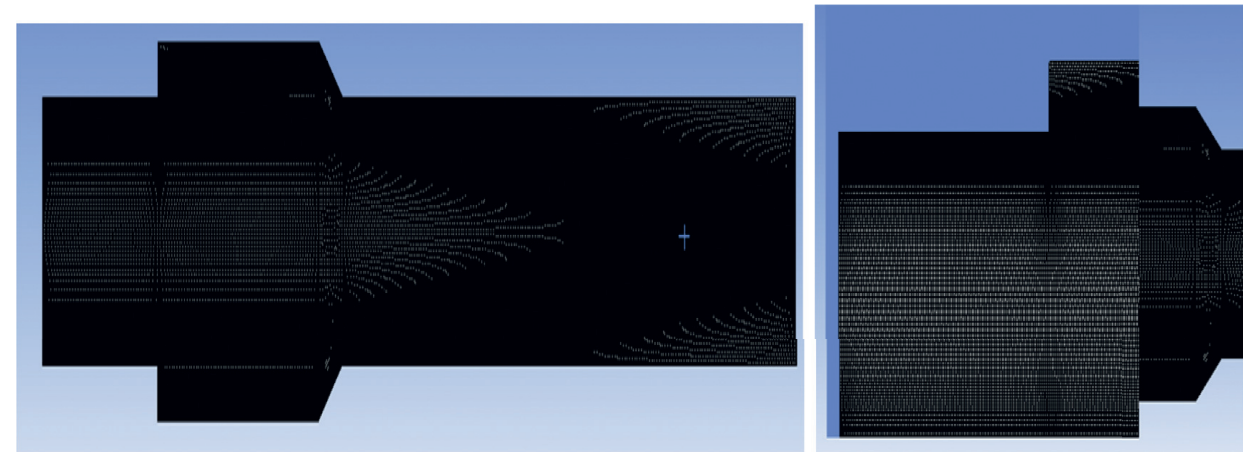

FIGURE 2: Generation of the final mesh for the parallel cavity scramjet combustor.

an ideal gas. The use of finite-rate dissipation evades the Arrhenius calculations and also reduces the computational time and cost. An implicit second-order unwinding scheme is used for spatial discretization.

For any kind of compressible and steady-state flow, continuity, momentum, and energy equations are discussed.

Continuity equation:

$$
\frac{\partial \rho}{\partial t}+\frac{\partial}{\partial x_{i}}\left(\rho u_{i}\right)=0, \quad \text { where } i=1,2,3 .
$$

Momentum equation:

$\frac{\partial}{\partial t}\left(\rho u_{i}\right)+\frac{\partial}{\partial x_{i}}\left(\rho u_{i} u_{j}\right)=-\frac{\partial P}{\partial x_{i}}+\frac{\partial}{\partial x_{i}}\left(\tau_{i, j}\right), \quad$ where $i, j=1,2,3$.

Energy equation:

$$
\frac{\partial}{\partial t}(\rho H)+\frac{\partial}{\partial x_{i}}\left(\rho u_{j} H\right)=\frac{\partial}{\partial x_{i}}\left(\tau_{i j} u_{i}-q_{i}\right), \quad \text { where } i, j=1,2,3,
$$

where $q_{i}=$ heat flux vector $q_{i}$ due to conduction and convection. Also,

$$
q_{i}=-\lambda \frac{\partial T}{\partial x_{i}}+\rho \Sigma_{k-1} h_{k} Y_{k} u_{j, k}
$$
law:

The diffusion velocities $u_{j, k}$ are calculated using Fick's

$$
Y_{k} u_{j, k}=-D_{k, m} \frac{\partial}{\partial x_{i}} Y_{k}
$$

The stress tensor can be estimated from the Boussinesq hypothesis, which gives a relationship between Reynolds stresses and mean strain tensor, which can be given as follows:

$$
\tau_{i j}=\left(\mu_{l}+\mu_{t}\right)\left[\frac{\partial u_{i}}{\partial x_{j}}+\frac{\partial u_{j}}{\partial x_{i}}-\frac{2}{3} \delta_{i j} \frac{\partial u_{k}}{\partial x_{k}}\right]-\frac{2}{3} \rho K \delta_{i j},
$$

where total viscosity, $\mu=\mu_{l}+\mu_{t}$, where $l$ and $t$ represent laminar and turbulent.

With the help of Sutherland law,

$$
\mu_{l}=\mu_{\mathrm{ref}}\left[\frac{T}{T_{\mathrm{ref}}}\right]^{3 / 2}\left[\frac{T_{\mathrm{ref}}+S}{T+S}\right]
$$

where $T$ =temperature of $\mu_{\text {ref }}$ and $T_{\text {ref }}$ and $S$ are known constants.

The conduct of the species in the reaction is studied with the species transport conservation governing equation which is discussed in the following.

Species conservation governing equation:

$$
\frac{\partial}{\partial t}\left(\rho Y_{i}\right)+\frac{\partial}{\partial x_{j}}\left(\rho u_{i} Y_{i}\right)=\frac{\partial}{\partial x_{j}}\left(\rho u_{i} Y_{i}\right)+w_{i},
$$


where $\rho$ =density; $u_{i}=$ velocity components; $Y_{i}=$ mass fraction of chemical species; and $w_{i}=$ chemical source term of species $i$.

The introduction of turbulence in the compressible flow equation leads to the induction of two equations, as discussed in the following.

Turbulent kinetic energy $(K)$ :

$$
\frac{\partial}{\partial t}(\rho K)+\frac{\partial}{\partial x_{k}}\left(\rho u_{k} K\right)=\frac{\partial}{\partial x_{k}}\left[\left(\frac{\mu_{l}}{P r}+\frac{\mu_{t}}{\sigma_{k}}\right) \frac{\partial K}{\partial x_{k}}\right]+S_{K} .
$$

Turbulent dissipation rate $(\epsilon)$ :

$$
\begin{aligned}
\frac{\partial}{\partial t}(\rho \epsilon)+\frac{\partial}{\partial x_{k}}\left(\rho u_{k} \epsilon\right) & =\frac{\partial}{\partial x_{k}}\left[\left(\frac{\mu_{l}}{P r}+\frac{\mu_{t}}{\sigma_{\epsilon}}\right) \frac{\partial \epsilon}{\partial x_{k}}\right]+S_{\epsilon}, \\
S_{K} & =\tau_{i j} \frac{\partial u_{i}}{\partial x_{K}}-\rho \epsilon, \\
S_{\epsilon} & =C_{e_{1}} \tau_{i k} \frac{\partial u_{i}}{\partial x_{k}}-C_{e_{2}} \frac{\rho \epsilon^{2}}{K} .
\end{aligned}
$$

Turbulent shear stress: $\tau_{i k}=\mu_{t}\left(\left(\partial u_{i} / \partial x_{k}\right)+\left(\partial u_{k} / \partial x_{i}\right)\right)$.

The coefficients used in abovementioned equations are stated in Table 1.

3.2. Combustion Modeling. To analyze the combustion process, the paper uses a species transport equation along with a finite-rate/eddy dissipation reaction equation is used. The combustion modeling utilizes the commonly used single-step kinematic model [44]. This paper deals in understanding the flow field characteristics and performance for different incoming Mach numbers; the single-step kinematic model has been proven to have fewer complications and show results in less computational time. The combustion reaction involved is given in the following:

$$
2 \mathrm{H}_{2}+\mathrm{O}_{2} \longrightarrow 2 \mathrm{H}_{2} \mathrm{O}
$$

\section{Boundary Conditions}

The defining of proper boundary conditions is an important step to achieve accuracy in any numerical simulation problem. In this paper, vitiated air enters the combustion chamber at $1486 \mathrm{~K}$ total temperature and pressure of 1.6 MPa. Dirichlet boundary conditions are applied to the inlet of the vitiated air and fuel injection. For the wall, noslip boundary conditions with zero heat flux are considered. The outflow boundary is allotted as a pressure outlet condition. The details of the values employed in the simulations are given in Table 2. Mostly, supersonic flow characteristics are obtained in the flow field. Therefore, for obtaining stability in the residuals, Courant-Friedrichs-Lewy's number is defined as 0.5 .

Assumptions are given as follows:

(1) Steady-state compressible flow is considered in this paper
TABLE 1: K- $\varepsilon$ coefficients used in the simulation.

\begin{tabular}{lccccc}
\hline Coefficients & $C_{e_{1}}$ & $C_{e_{2}}$ & $C_{\mu}$ & $\sigma_{k}$ & $\sigma_{\epsilon}$ \\
\hline Values & 1.44 & 1.92 & 0.09 & 1.0 & 1.3 \\
\hline
\end{tabular}

(2) The 2-dimensional analysis is considered to save computational time

(3) The turbulence in the flow field is address by using the standard 2-equation $\mathrm{K}-\varepsilon$ model

(4) Ideal gas laws are assumed

\section{Validation and Grid Independence Study}

5.1. Validation. For numerical simulation problems, validation and grid independence study are very important aspects of the study. The selection of the appropriate computational model for better accuracy and reliability of the computational results for a certain application is very necessary. Therefore, a comparison of the experimental and simulation results and close visualization of the obtained results justify the reliability of the selected computational code. In this paper, the Ansys Fluent 15.0 is selected as the computational software to carry out the simulations. The present research work is validated from two different experimental scramjet configurations.

Firstly, the results of the present simulations are compared with the combined experimental and numerical work operated by Yang et al. [37, 39]. The experiments were conducted at the National University of Defence Technology. The setup consists of a combustor inlet.

Connected through a nozzle having $M=2.52$, the parallel cavity configuration was achieved by installing the same cavity on both walls having a cavity depth of $8 \mathrm{~mm}$. The qualitative affirmation of the simulated results was done by comparing the results with the Schlieren and flame luminosity images of the experiment, as shown in Figure 3(a). Furthermore, the computational static pressure distribution along the top wall of the combustor was compared with the experimental and numerical results obtained from the experiment. The static pressure distribution along the upper wall is shown in Figure 3(b). The computational results show a satisfactory level of agreement on comparing it with the numerical and experimental results obtained from the experiment. However, a slight deviation was observed in predicting the shock waves behavior due to computation error. The first two points of the upper cavity wall displayed a pressure of around $180 \mathrm{KPa}$, and the remaining points displayed a pressure of around $170 \mathrm{KPa}$, which are rather underestimated by computational results. The pressure contour indicates that the recirculation region exhibits maximum pressure due to the continuous combustion phenomenon.

The other validation is carried out with the DLR scramjet combustor experimentally tested by Waidmann et al. [45] at the German Aerospace Laboratory and the simulations of the complex flow field were carried by Oevermann [46] as shown in Figure 4. The combustor consists of a triangular strut from where the hydrogen fuel was injected. The cross-stream 
TABLE 2: Boundary conditions used in the simulations.

\begin{tabular}{|c|c|c|c|c|}
\hline S. no. & & Variables & Air & Hydrogen fuel \\
\hline 1 & Mach number & $M$ & $2.25 ; 2.52 ; 2.75$ & 1 \\
\hline 2 & Total pressure & $P_{o}(\mathrm{KPa})$ & 1600 & 630 \\
\hline 3 & Total temperature & $T_{o}(\mathrm{~K})$ & 1486 & 300 \\
\hline 4 & Turbulent kinetic energy & $K\left(\mathrm{~m}^{2} / \mathrm{s}^{2}\right)$ & 10 & 2400 \\
\hline 5 & Turbulent dissipation rate & $\left(\mathrm{m}^{2} / \mathrm{s}^{3}\right)$ & 650 & $1 e+8$ \\
\hline \multicolumn{5}{|c|}{ Concentration of species } \\
\hline 6 & Hydrogen mass fraction & $\mathrm{Y}_{\mathrm{H}_{2}}$ & 0 & 1 \\
\hline 7 & Oxygen mass fraction & $\mathrm{Y}_{\mathrm{O}_{2}}^{11_{2}}$ & 0.2338 & 0 \\
\hline 8 & Nitrogen mass fraction & $\mathrm{Y}_{\mathrm{N}_{2}}$ & 0.704 & 0 \\
\hline 9 & Water mass fraction & $\mathrm{Y}_{\mathrm{H}_{2} \mathrm{O}}$ & 0.0622 & 0 \\
\hline
\end{tabular}

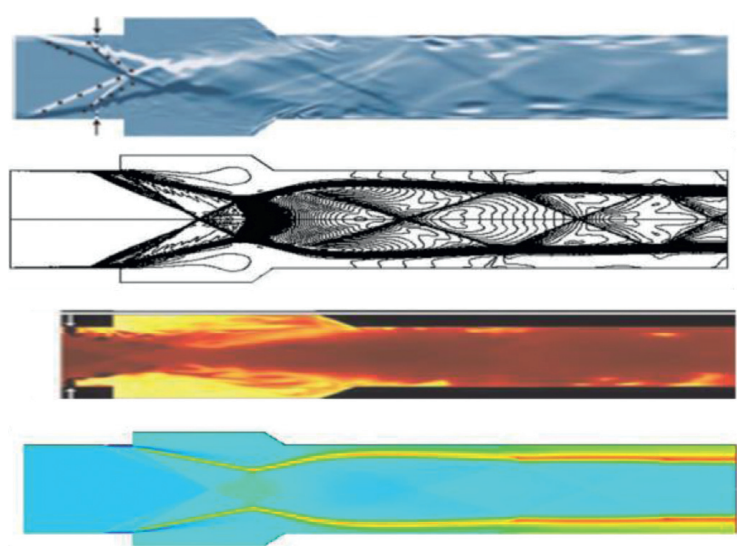

(a)

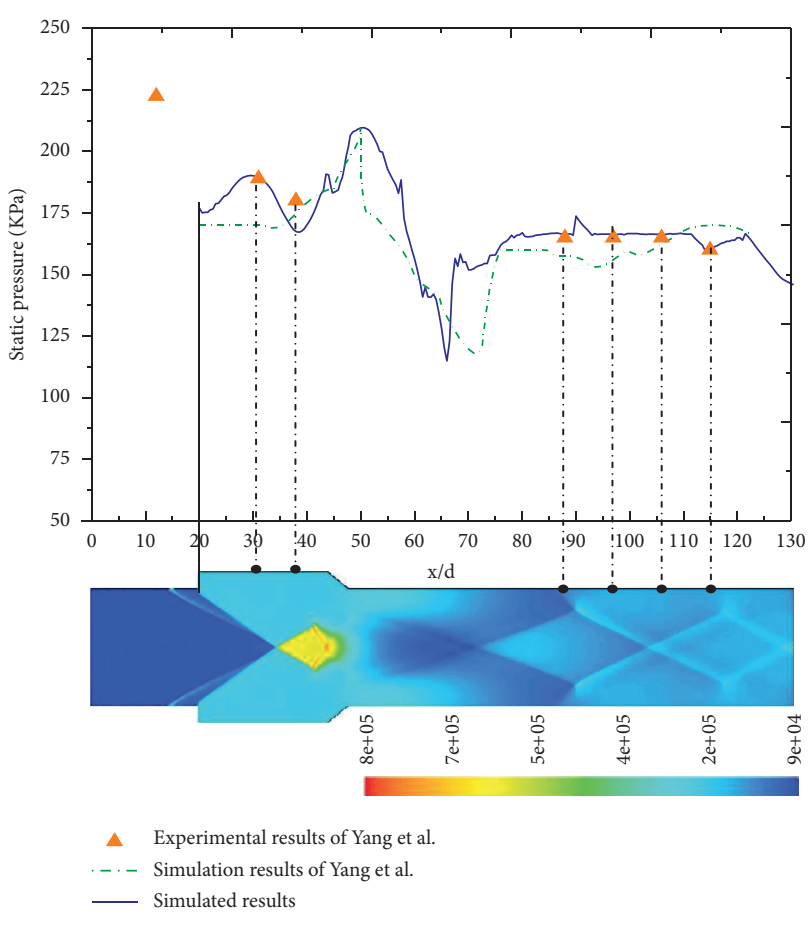

(b)

Figure 3: (a) Comparisons of the Schlieren images and flame luminosity images with the density and temperature contours obtained from the simulations. (b) Static wall distribution along the upper wall of the cavities and comparing the experimental and simulation work with the present simulations.

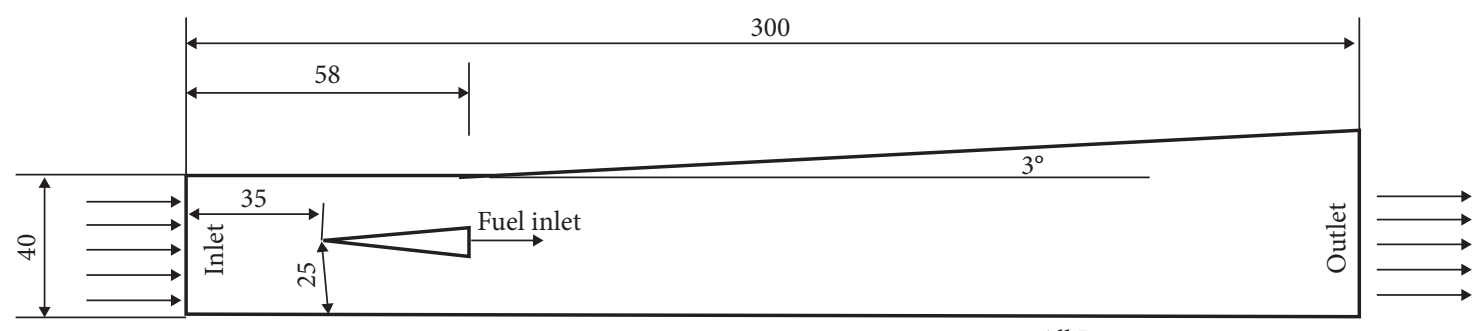

All Dimensions are in $\mathrm{mm}$

FIgURE 4: Schematic diagram of the DLR scramjet combustor.

velocity profiles at $x=125 \mathrm{~mm}$ and $207 \mathrm{~mm}$ are presented in Figures 5(a) and 5(b); the experimental and computational results are in good accord with each other. However, at streamwise location $x=207 \mathrm{~mm}$ downstream, the fuel jet (hydrogen), due to longer acceleration, achieves higher inner velocity than the adjacent upper and lower air stream 


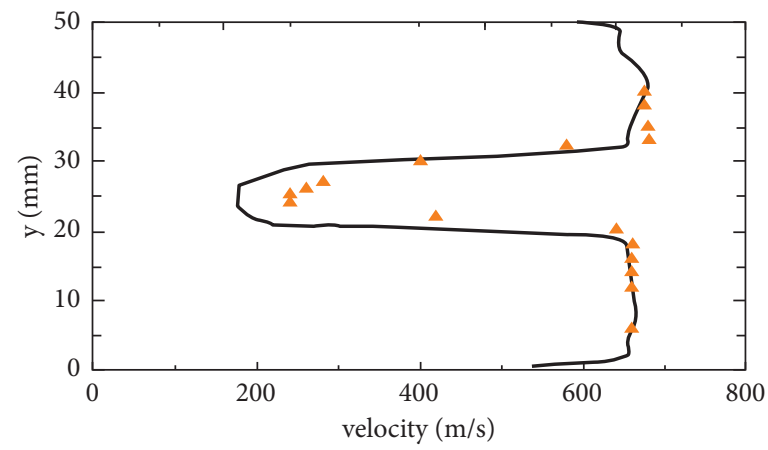

_ Silmulation results for $\mathrm{x}=125 \mathrm{~mm}$

- Experimental results for $\mathrm{x}=125 \mathrm{~mm}$

(a)

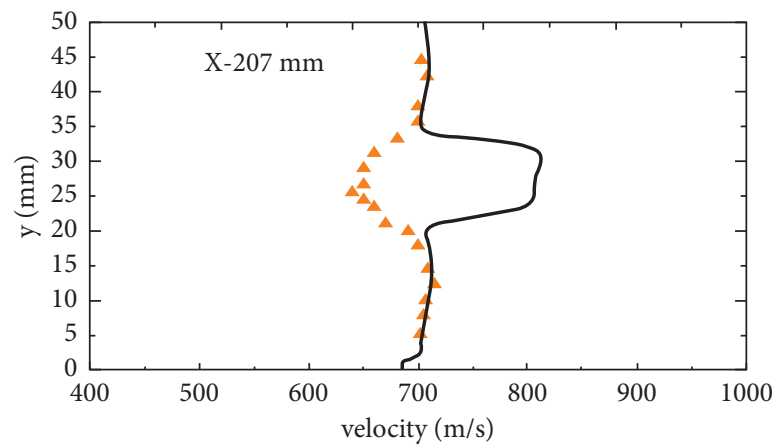

- Simulation results

- Experimental results

(b)

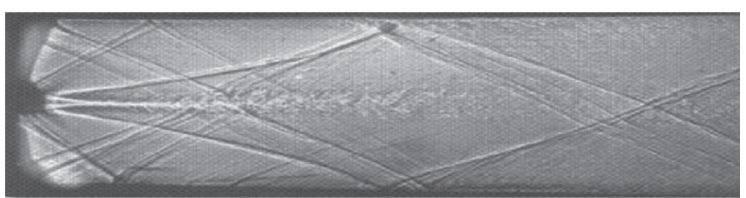

(c)
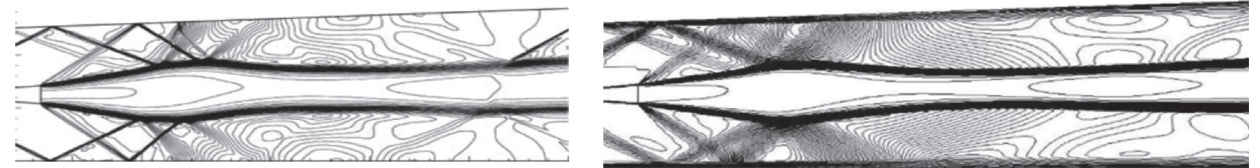

(d)
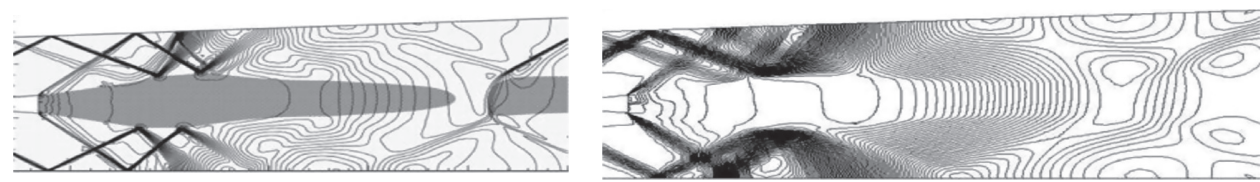

(e)

FIGURE 5: Comparison of the experimental and simulation velocity profiles at streamwise locations (a) $125 \mathrm{~mm}$ and (b) $207 \mathrm{~mm}$. Comparison of the experimental (c) shadow image with the contours of the (d) density and (e) pressure.

velocities which results in a disparity between the experimental and computational results. The qualitative validation of the simulation results is done by comparing the shadow images and the density and pressure contours obtained from
Oevermann [46] simulation, as shown in Figures 5(c)-5(e). The flow characteristics and generation of shock waves of the scramjet combustor for both configurations are in good agreement with the experimental results. 
5.2. Grid Independence Study. The computational simulation is greatly affected by meshing; the grid independence study helps to identify the appropriate grid size for the current simulation to get optimum results. In this paper, three different grids are considered, namely coarse (130023 elements), moderate (458535 elements), and fine grid (717900 elements).

The fine grid was refined by introducing an inflation layer near the walls. The higher the grid size, the higher the computational time. The grid independence study is achieved by plotting the static pressure distribution of the upper wall along the length for all three grids. Figure 6 shows that there were very minute changes in the wall static pressure on comparing among the three grids. However, it is seen from Figure 6 that the numerical simulation pressure is underestimated at certain points, but overall satisfactory variation is observed. Furthermore, the solution tends not to change after 717900 elements.

\section{Results and Discussion}

The mixing behavior of the fuel-air mixture and the velocities of both fuel and air are in close association while studying the characteristics of combustion. The most essential conditions for efficient combustion are appropriate burning of fuel and air and complete disassociation of fuel into the air stream. The combustion phenomenon is said to be started when the hydrogen molecules start disassociating to the oxygen molecules to complete the chemical kinematics. At this point, heat release is observed. In the scramjet combustion phenomenon, the most crucial challenge is achieving a stable flame. Implementation of flame holder mechanisms in the combustor helps in generates low eddies, which helps in flame stability. In this research paper, a twodimensional scramjet combustor with parallel cavities is modeled and investigated computationally using Ansys FLUENT 15.0. The prime focus of the computational study is to flow field behavior of the blend in the combustor for different Mach numbers. Furthermore, we seek to understand the physics behind the formation of shock waves and the importance of the formation of recirculation regions. To understand the behavior of shock waves and their effects on various variables, different inlet air stream Mach numbers are employed, such as $2.25,2.52$, and 2.75. A section on the performance parameters is also presented for a more precise understanding of the variables.

6.1. Characteristics of the Flow Field. As stated earlier, the supersonic combustor flow field is complex and has very little time available for the mixing of fuel and air. It is very necessary to understand the different properties that influence the performance of the combustor, such as the formation of the shear layer and recirculation region, interaction of shock waves, formation of reattachment shock waves, etc. The air-breathing engines work on the Brayton cycle, but these engines do not have any moving parts. For completion of this thermodynamic cycle, the properties are solely responsible for creating the necessary environment

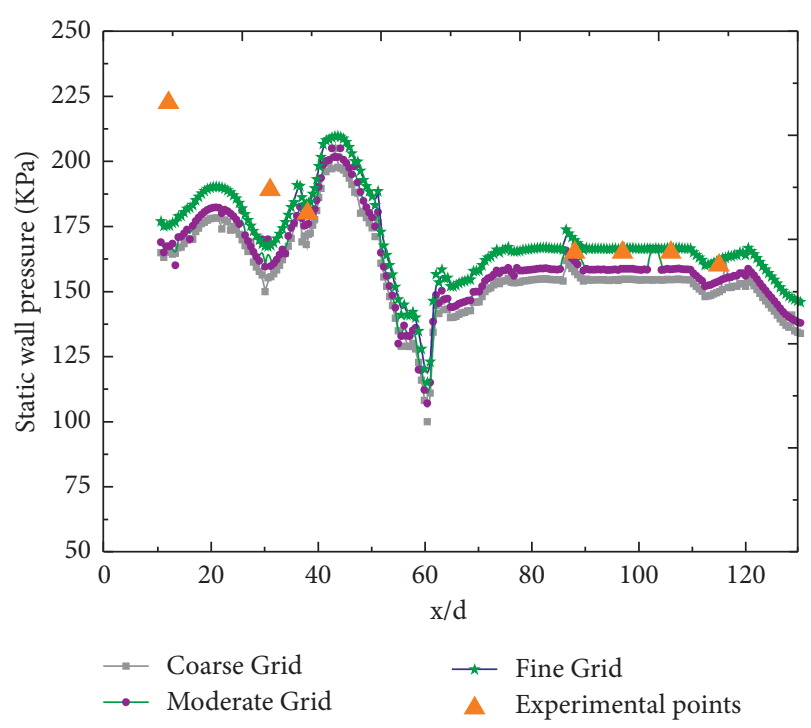

FIGURE 6: Grid independence test (static pressure distribution along the upper wall).

inside the combustor. Another property that influences the combustion process in a scramjet is the efficient disassociation among the species. In the section below, the influence of different variables on the combustion characteristics are stated.

6.1.1. Behavior of Shock Waves. The shock waves are strong pressure waves that are produced due to evident disturbances in a medium that propagates faster than the speed of sound. In scramjet combustion, the formation of shock waves inside the combustor is an important episode, as it compresses the incoming air causing the pressure and temperature to rise. In this paper, three different incoming Mach numbers are considered to understand the behavior of shock waves. For a proper understanding of the behavior of shock waves, a nomenclature of shock waves behavior is shown in Figure 7. When the incoming air comes in contact with the initial injection of fuel, oblique shock waves are formed. This shock wave formation helps in the compression of the fuel. Another shock wave is initiated from the leading of the cavities, which is a bow shock wave. This causes shockshock waves interaction, which pushes the fuel-air blend into the parallel cavities. Recirculation regions are regions of high pressure. The region is formed when the fuel is first injected and blends with the incoming air. High-pressure vortices are created that are observed to be cornered at the parallel cavities. The recirculation region plays an important role in fuel-air mixing. The formation of a shear layer is observed after fuel injection that causes the presence of a subsonic region in the combustor, which is helpful in combustion sustainment and flame holding. At this point, shock-shear layer interaction is observed. The interaction of bow and oblique shock waves and reattachment shock waves are observed downstream, which results in high-pressure peaks. A comparison study is presented among all Mach numbers through Mach number, and density contours are shown in 


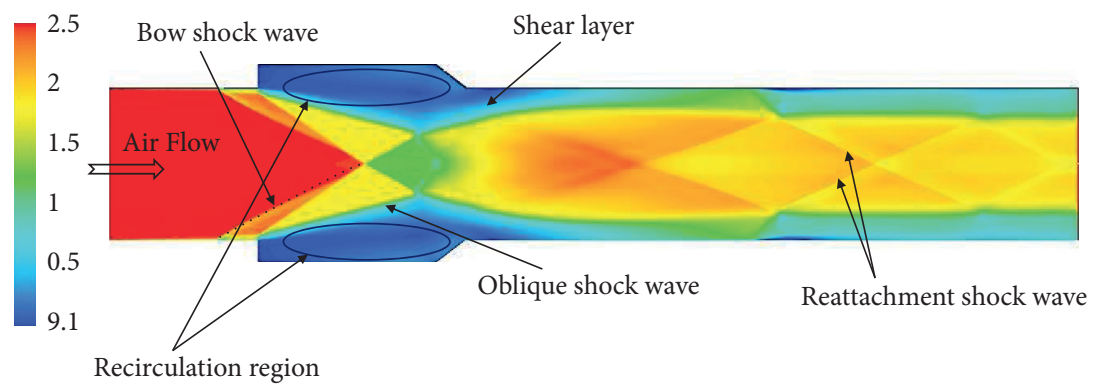

FIGURE 7: Mach number contour showing the nomenclature of the shock waves and their interactions.

Figures 8 (a) and $8(\mathrm{~b})$, respectively. In all the cases, the clear formation of shock waves is observed. It is observed that the first shock waves formed when the incoming air comes in contact with the fuel. The clear change in the behavior of the recirculation region and change in shear layer activities in all the cases are seen in the Mach number contours. The contours of the Mach number indicate the Mach number of the incoming air is initially constant before encountering the fuel. The formation of the recirculation region in the parallel cavities represents the proper mixing of fuel and air. However, the recirculation region tends to move downstream with an increase in Mach number. It is to be noted that for $M=2.25$ and 2.52, stronger combustion is observed as compared to $M=2.75$. The density contours for all the Mach numbers show the angle between the bow shock formed after fuel injection and the trailing edge of the cavities are decreasing with the increase in the incoming Mach number. This reason explains the behavior of the recirculation regions moving downstream with an increase in incoming Mach number.

6.1.2. Effect of Mach Number on Temperature. The present computational work is based on different Mach numbers such as $2.25,2.52$, and 2.75 . The temperature contours are a parameter to check the efficiency of the combustion process. The interpretation for efficient combustion is that the occurrence of a greater amount of oxidation of fuel increases the static pressure. The static temperature contours for all the cases are shown in Figure 9(a). The contours reveal that the temperature distribution concentration along the combustor walls is developed far downstream towards the end of the combustor, which is not very accurate. For all the Mach numbers, the process of combustion is started after the first injection of hydrogen fuel and the combustion is contained in between the cavities of the combustor. However, a slight spreading of combustion is observed downstream in all the cases. For $M-2.52$ and 2.75, the concentration of temperature distribution along the wall is developed towards the end of the combustion. However, for $M-2.25$, the concentration of temperature is observed to be spread downstream the cavities which are not ideal for better performance.

Furthermore, at $M=2.25$, stronger bow shock waves interaction is observed at the combustor. The bow shock interactions are observed to be weakened with an increase in Mach numbers. Therefore, the combustion tends to spread downstream for $M=2.52$ and 2.75. It is seen observed from the contours that the temperature value increases with an increase in Mach number, but after a certain point, it tends to decrease. The highest temperature of $2711.467 \mathrm{~K}$ was observed for $M=2.25$ as compared to the remaining Mach numbers.

6.1.3. Effect of Mach Number on Pressure. The pressure contours follow the density contours very closely. The contours indicate the generation of shock waves and the mixing of fuel and air. The static pressure contours of the combustor are shown in Figure 9(b). The contours show a sudden rise in pressure after injection of fuel irrespective of Mach number. The generation of bow shock leads to an increase in the pressure which is due to the transverse fuel injection technique. This results in air compression, which leads to high-pressure creation. The shock waves interaction generates regions of high pressure at the center of the combustor. The high-pressure region results in the creation of immense gradients of pressure that knocks the fuel towards the wall of the combustor. Towards the downstream of the combustor, reattachment shock waves and their interaction with the bow and initial shock waves are visible in the contours. Figure 9(c) gives a hint of the explanation.

6.1.4. Effect of Mach Number on $\mathrm{H}_{2} \mathrm{O}$ Mass Fraction. The variation mass fraction contours of $\mathrm{H}_{2} \mathrm{O}$ are represented in Figure 10 for all Mach numbers. These contours show very closely with the temperature contours. From close observation of the contours, it is seen that the process of combustion has been started with the injection of the fuel. The presence of high concentrations of $\mathrm{H}_{2} \mathrm{O}$ is seen at the cavities and starts to fade downstream for all incoming Mach numbers. The high presence concentration of $\mathrm{H}_{2} \mathrm{O}$ represents that the combustion is taking place. Also, $\mathrm{H}_{2} \mathrm{O}$ is the only product obtained from the single-step combustion reaction. From the contours, it is observed that the $\mathrm{H}_{2}$ penetration is seen to be maximum at the central portion of the combustor irrespective of the Mach numbers. The flow gains its acceleration towards the end of the parallel cavities for $M-2.52$ and 2.75. The maximum penetration $\mathrm{H}_{2}$ into the airstream was observed for $M-2.52$ and 2.75 , respectively. Meanwhile, for $M-2.25$, the fuel penetration was observed less after the injection of the fuel. The mass fraction concentration of $\mathrm{H}_{2} \mathrm{O}$ was initially the same at the entry of the 


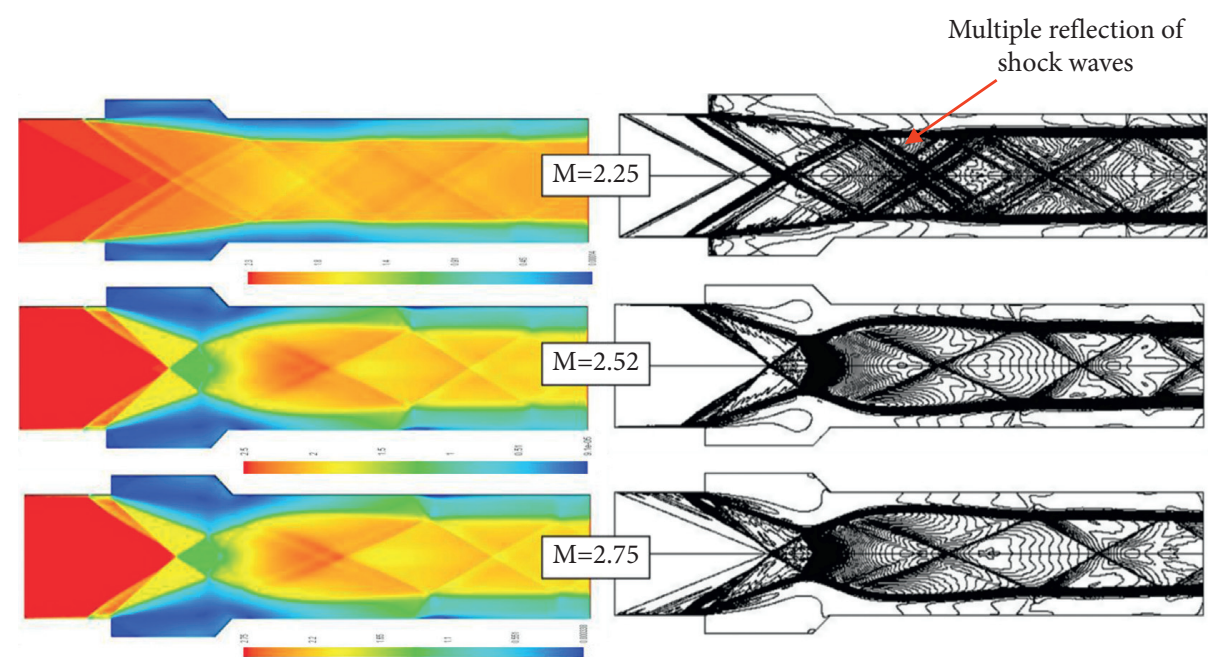

Figure 8: (a) Mach number contours for different incoming Mach numbers. (b) Contours plot of density for different incoming Mach numbers.

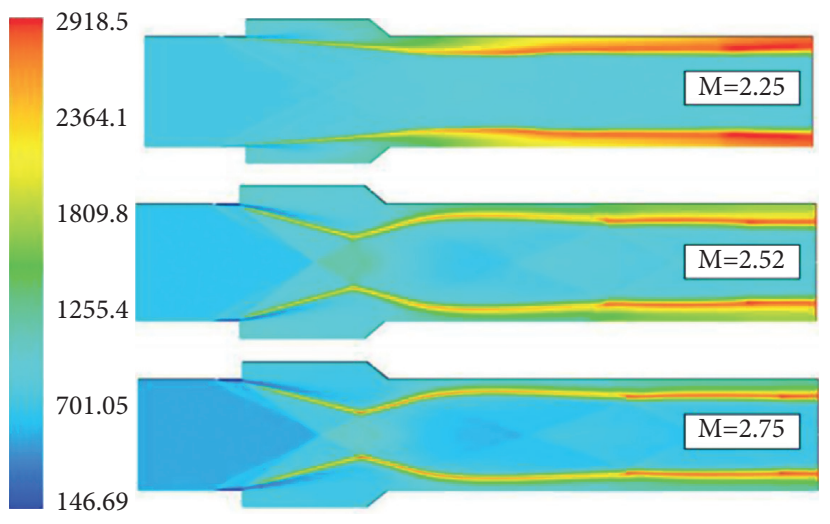

(a)

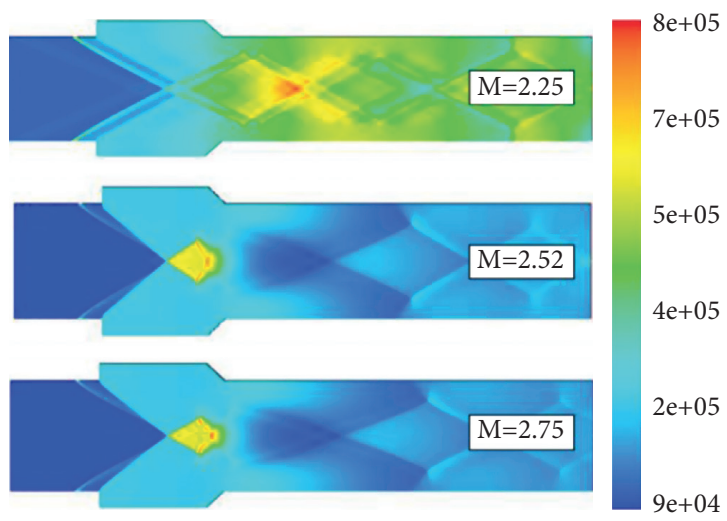

(b)

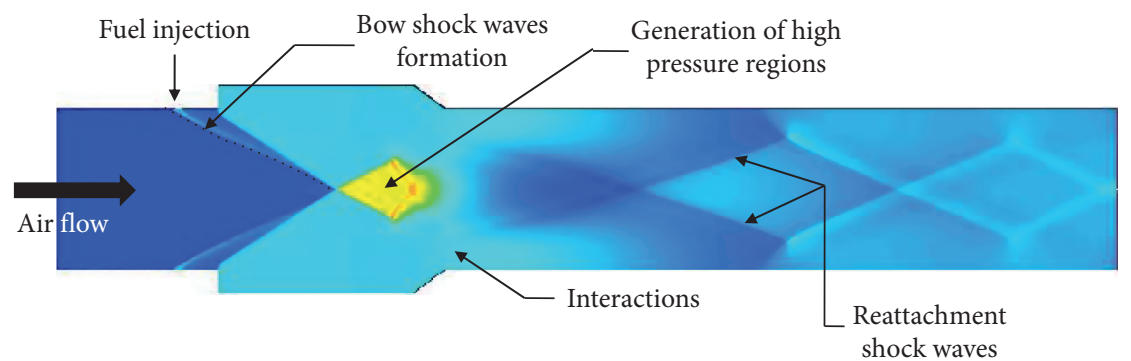

(c)

Figure 9: Contour plot of (a) temperature, (b) pressure at different incoming Mach numbers, and (c) pressure for Mach 2.52 describing the different shock waves formations and flow variables.

combustion and tended to increase in the lateral direction for any cross-sectional area if taken. This provides a clear indication that the combustion efficiency is also increasing along the length of the combustor.

6.2. Performance Parameters. In the previous section, flow field characteristics were discussed along with their effects on various parameters that influence the combustion process. The estimation of the characteristics of any system is not complete without the overall performance parameters. The performance parameters considered in the study are stated in the section below.

6.2.1. Combustion Efficiency. In this paper, combustion efficiency is one of the parameters selected for the estimation of the combustion process. The combustion efficiency as described by [47] is defined as follows: 


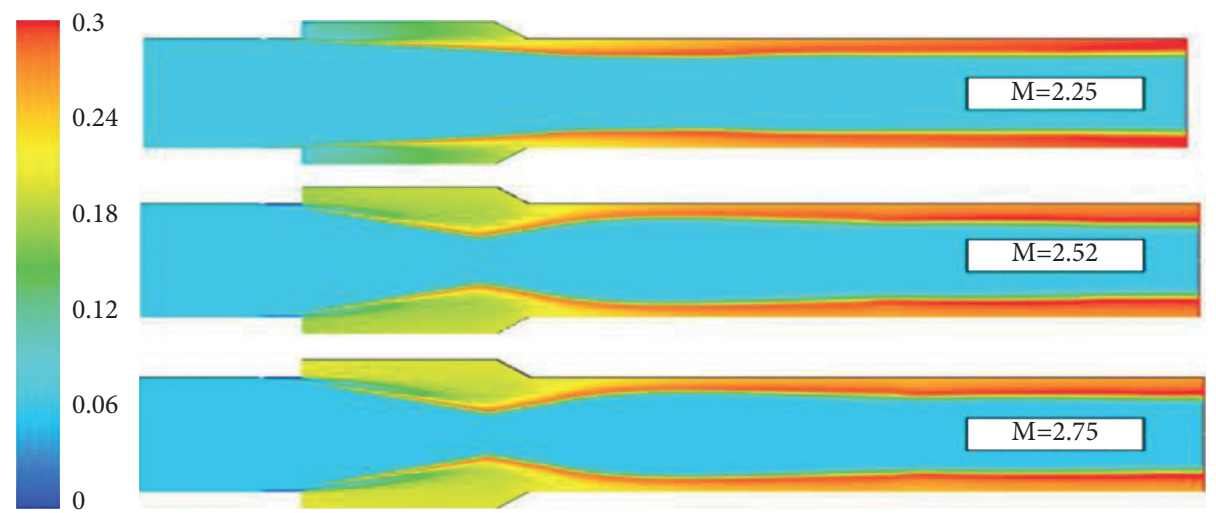

Figure 10: Contour plot of $\mathrm{H}_{2} \mathrm{O}$ mass fraction at different incoming Mach numbers.
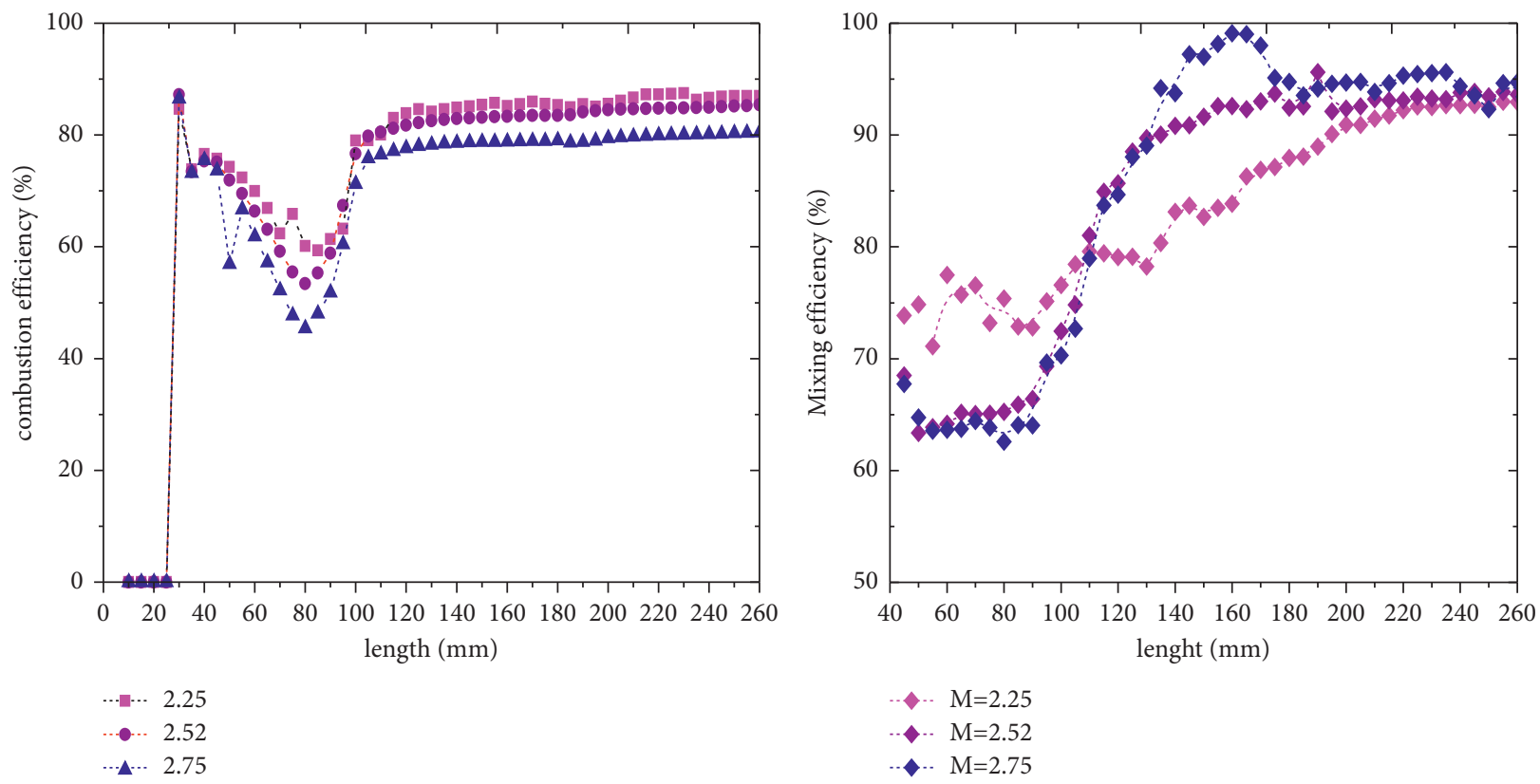

Figure 11: Combustion and mixing efficiencies for different Mach numbers.

$$
\begin{aligned}
\eta_{c}(x) & =\frac{\dot{m}_{H 2, \text { jet }}-\int A(x) \rho Y_{H 2} U d A}{\dot{m}_{H 2, \text { jet }}} \\
& =1-\frac{\int A(x) \rho Y_{H 2} U d A}{\dot{m}_{H 2, \text { jet }}}=1-\frac{\dot{m}_{H 2, x}}{\dot{m}_{H 2, j e t}},
\end{aligned}
$$

where $\eta_{c}(x)$ is the combustion efficiency, $\dot{m}_{H 2, x}$ is the mass flow of hydrogen fuel at the selected cross-section, $\dot{m}_{H 2 \text {, jet }}$ is the mass flow rate of injected hydrogen fuel, $A(x)$ is the cross-sectional area at different locations $x$, and $\rho, Y_{H_{2},} U$ are density, mass fraction of hydrogen, and velocity, respectively. Figure 11 shows the combustion efficiency plot for the different incoming Mach numbers. It has been identified from the graph that for all the Mach numbers, there was a steep increase in combustion efficiency somewhere near the parallel cavities. However, the combustion efficiency seemed to be uniform with minute variation downstream due to the absence of recirculation region and lower heat release. The maximum combustion efficiency is $87.74 \%$ for $M=2.25$.
6.2.2. Mixing Efficiency. The proper mixing of the species in a combustion reaction is very essential for obtaining the desirable heat release. In this paper, $\phi=1$ is used for evaluating the mixing of fuel and air. The presence of a high equivalence ratio $(\phi=1)$ is highly affected by the mixing of fuel and air. Mixing efficiency is defined as the ratio of the hydrogen mass flux that is to be burnt to the total mass flux of hydrogen injected as described by [48] stated as follows:

$$
\eta_{\text {mix }}=\frac{\int_{A} \alpha \rho u Y_{H 2} d A}{\int_{A} \rho u Y_{H 2} d A}=\frac{\int_{A} \alpha \rho u Y_{H 2} d A}{\dot{m}_{H 2, x}} ; \alpha=\left\{\begin{array}{c}
\frac{1}{\phi} \phi>1 \\
1 \quad \phi<1
\end{array}\right\},
$$

where $\phi$ is the equivalence ratio.

The mixing efficiency shows the expected fuel burnt under stoichiometric conditions along the combustor length. Figure 11 shows the mixing efficiency for all three Mach numbers after the fuel injection. In the plot, after the 
fuel injection mixing efficiency increase monotonously due to the rapid mixing of the fuel in the air stream for all three Mach numbers. Furthermore, downstream parallel cavities, there is again an increase in mixing efficiency, which increases a maximum of about $98 \%$ for $M-2.75$. However, for $M-2.25$ and 2.52, the mixing efficiency downstream the cavities reach around $90 \%$ and $95 \%$ for Mach 2.25 and 2.52 , respectively. On moving towards the downstream of the combustor, the mixing efficiency is observed to be stable, showing mixing efficiency of around $90-100 \%$, which is a considerable condition for enhancing the engine performance. It is visible from the plot that the maximum mixing efficiency was obtained for $M=2.75$. Due to the geometry of the combustor, $100 \%$ mixing of the fuel and air was not achieved. However, $98.15 \%$ mixing efficiency is achieved for $M=2.75$.

\section{Conclusions}

The paper investigates the flow field characteristics and performance parameters for Mach 2.25, 2.52, and 3.0 for a parallel cavity scramjet combustor computationally using Ansys Fluent 15.0. The effect of Mach numbers on various parameters was also studied. All the simulations are carried out for two-dimensional compressible RANS equations. The results are accorded in the form of pressure, temperature, $\mathrm{H}_{2} \mathrm{O}$ mass fractions, mixing efficiency, and combustion efficiency for the three incoming Mach numbers. The following conclusion was drawn from the findings:

(i) It was observed from the validations that the models exhibit fairly in predicting the experimental results, taking into consideration the computational time and error. The wall static pressure variation along the length shows acceptable outcomes with the experimental results. Also, the cross-stream velocity profile of the DLR scramjet combustion at $x=125 \mathrm{~mm}$ and $207 \mathrm{~mm}$ locations shows suitable agreement with the experimental results. Furthermore, both validations, on comparing the schlieren images and simulation images, showed good agreement with each other.

(ii) The contours of the temperature for different Mach numbers clearly show the formation of high-temperature regions near the walls. The interaction of bow shock waves is observed stronger for $M=2.25$ and gets weak as the Mach number increases. At $M=2.25$, the highest temperature of $2711 \mathrm{~K}$ was observed.

(iii) The pressure contour shows similar variations with the density contours. For all the Mach numbers, the pressure contours clearly show a rise in pressure after injection of the fuel. It can also be seen from the contours that the high-pressure region is formed at the center of the combustor reason being shockshock wave interaction. The highest pressure rise of 833159.6 Pa was observed for $M=2.52$ (iv) The effect of Mach number on the $\mathrm{H}_{2} \mathrm{O}$ mass fractions shows that the combustion process was initiated with the first injection of the hydrogen fuel. A consistent combustion process was observed for all Mach numbers. The contours show the presence of high concentrations of $\mathrm{H}_{2} \mathrm{O}$.

(v) The maximum combustion and mixing efficiency was observed for $M-2.25(87.47 \%)$ and $M=2.75$ (98.15\%), respectively.

\section{Future Scope}

(i) The development of 3-dimensional models for a more detailed study of geometry can be taken into consideration.

(ii) The development of a 3D model also paves the way to use LES modeling. However, the LES modeling on this model has already been discussed in the literature. However, the LES modeling can be used to discover other aspects of the same model.

(iii) An in-depth study on the formation of boundary and separation inside the flow field of the combustor has enough scope for future research.

\section{Data Availability}

The data from software analysis can be obtained upon request to the corresponding author.

\section{Conflicts of Interest}

The authors declare that they have no conflicts of interest.

\section{Acknowledgments}

The authors express their respect and acknowledgment to the Mechanical Engineering Department of National Institute of Technology, Silchar, and TEQIP-III for providing the Computational Laboratory to carry out the simulation work.

\section{References}

[1] E. T. Curran, "Scramjet engines: the first forty years," Journal of Propulsion and Power, vol. 17, no. 6, pp. 1138-1148, 2001.

[2] J. Hank, J. Murphy, and R. Mutzman, "The X-51A Scramjet engine flight demonstration program," in Proceedings of the 15th AIAA International Space Planes and Hypersonic Systems and Technologies Conference, Dayton, OH, USA, May 2008.

[3] A. M. Bonanos, C. P. Goyne, R. W. Barnwell, and J. J. Wang, "Scramjet operability range studies of an integrated hydrogen and hydrocarbon fuels," Dissertation thesis, Virginia Polytechnic Institute and State University, Blacksburg, VA, USA, 2005.

[4] A. Ferri, "Review of scramjet propulsion technology," Journal of Aircraft, vol. 5, no. 1, pp. 3-10, 1968.

[5] M. Dharavath, P. Manna, and D. Chakraborty, "Numerical simulation of hydrogen air supersonic coaxial jet," Journal of 
The Institution of Engineers (India): Series $C$, vol. 98, no. 5, pp. 575-585, 2017.

[6] W. P. Jones and J. H. Whitelaw, "Calculation methods for reacting turbulent flows: a review," Combustion and Flame, vol. 48, pp. 1-26, 1982.

[7] M. Sun, H. Wang, Z. Cai, and J. Zhu, "Introduction," in Unsteady Supersonic Combustion, pp. 1-55, Springer, Singapore, Asia, 2020.

[8] Z. Peng, J. Zanganeh, R. Ingle, P. Nakod, D. F. Fletcher, and B. Moghtaderi, "Effect of tube size on flame and pressure wave propagation in a tube closed at one end: a numerical study," Combustion Science and Technology, vol. 192, no. 9, pp. 1731-1753, 2020.

[9] Z. Peng, J. Zanganeh, E. Doroodchi, and B. Moghtaderi, "Flame propagation and reflections of pressure waves through fixed beds of RTO devices: a CFD study," Industrial \& Engineering Chemistry Research, vol. 58, no. 51, pp. 2338923404, 2019.

[10] Z. Peng, J. Zanganeh, R. Ingle, P. Nakod, D. F. Fletcher, and B. Moghtaderi, "CFD investigation of flame and pressure wave propagation through variable concentration methaneair mixtures in a tube closed at one end," Combustion Science and Technology, vol. 193, no. 7, pp. 1203-1230, 2021.

[11] S. Kumar Dixit, "Mathematical modeling and analysis of different type of fuel injector in scramjet engine using CFD simulation in fluent," International Journal for Research in Applied Science and Engineering Technology, vol. 5, pp. 379$389,2017$.

[12] R. Masumoto, S. Tomioka, K. Kudo, A. Murakami, K. Kato, and H. Yamasaki, "Experimental study on combustion modes in a supersonic combustor," Journal of Propulsion and Power, vol. 27, no. 2, pp. 346-355, 2011.

[13] W. Huang, Z.-G. Wang, S.-B. Luo et al., "Overview of fuel injection techniques for scramjet engines," Volume 2: Combustion, Fuels and Emissions, Parts A and B, vol. 2, pp. 17-24, 2011.

[14] Y. Tian, X. Zeng, S. Yang, F. Zhong, and J. Le, "Experimental study on the effect of equivalence ratio and injector position on flow structure and flame development in the scramjet combustor," Aerospace Science and Technology, vol. 82-83, pp. 9-19, 2018.

[15] M.-B. Sun, Z.-G. Wang, J.-H. Liang, and H. Geng, "Flame characteristics in supersonic combustor with hydrogen injection upstream of cavity flameholder," Journal of Propulsion and Power, vol. 24, no. 4, pp. 688-696, 2008.

[16] Q. Liu, D. Baccarella, W. Landsberg, A. Veeraragavan, and T. Lee, "Cavity flameholding in an optical axisymmetric scramjet in Mach 4.5 flows," Proceedings of the Combustion Institute, vol. 37, no. 3, pp. 3733-3740, 2019.

[17] W. Huang and L. Yan, "Numerical investigation on the ramscram transition mechanism in a strut-based dual-mode scramjet combustor," International Journal of Hydrogen Energy, vol. 41, no. 8, pp. 4799-4807, 2016.

[18] P. Gerlinger and D. Bruggemann, "Numerical investigation of hydrogen strut injections into supersonic airflows introduction," Journal of Propulsion and Power, vol. 16, no. 1, 2000.

[19] D. B. Le, C. P. Goyne, R. H. Krauss, and J. C. McDaniel, "Experimental study of a dual-mode scramjet isolator," Journal of Propulsion and Power, vol. 24, no. 5, pp. 1050-1057, 2008.

[20] K. Kumaran and V. Babu, "Investigation of the effect of chemistry models on the numerical predictions of the supersonic combustion of hydrogen," Combustion and Flame, vol. 156, no. 4, pp. 826-841, 2009.
[21] I. W. Kay, W. T. Peschke, and R. N. Guile, "Hydrocarbonfueled scramjet combustor investigation," Journal of Propulsion and Power, vol. 8, no. 2, pp. 507-512, 1992.

[22] C. Zhang, Q. Yang, J. Chang, J. Tang, and W. Bao, "Nonlinear characteristics and detection of combustion modes for a hydrocarbon fueled scramjet," Acta Astronautica, vol. 110, pp. 89-98, 2015.

[23] Q. Yang, J. Chang, and W. Bao, "Thermodynamic analysis on specific thrust of the hydrocarbon fueled scramjet," Energy, vol. 76, pp. 552-558, 2014.

[24] A. Ben-Yakar and R. Hanson, "Cavity flameholders for ignition and flame stabilization in scramjets-review and experimental study," in Proceedings of the 34th AIAA/ASME/ SAE/ASEE Joint Propulsion Conference and Exhibit, Cleveland, OH, USA, July 1998.

[25] A. Ben-Yakar and R. K. Hanson, "Cavity flame-holders for ignition and flame stabilization in scramjets: an overview," Journal of Propulsion and Power, vol. 17, no. 4, pp. 869-877, 2001.

[26] D. Cecere, E. Giacomazzi, N. M. Arcidiacono, and F. R. Picchia, "Direct numerical simulation of a turbulent lean premixed $\mathrm{CH} 4 / \mathrm{H} 2$-Air slot flame," Combustion and Flame, vol. 165, pp. 384-401, 2016.

[27] A. Amid, D. Mignard, and M. Wilkinson, "Seasonal storage of hydrogen in a depleted natural gas reservoir," International Journal of Hydrogen Energy, vol. 41, no. 12, pp. 5549-5558, 2016.

[28] W. Huang, "Effect of jet-to-crossflow pressure ratio arrangement on turbulent mixing in a flowpath with square staged injectors," Fuel, vol. 144, pp. 164-170, 2015.

[29] D. J. Micka and J. F. Driscoll, "Combustion characteristics of a dual-mode scramjet combustor with cavity flameholder," Proceedings of the Combustion Institute, vol. 32, no. 2, pp. 2397-2404, 2009.

[30] R. Milligan, D. Eklund, J. Wolff, T. Mathur, and M. Gruber, "Dual mode scramjet combustor: analysis of two configurations," in Proceedings of the 48th AIAA Aerospace Sciences Meeting Including the New Horizons Forum and Aerospace Exposition, pp. 1-19, Orlando, FL, USA, January 2010.

[31] X. Li, W. Liu, Y. Pan, L. Yang, B. An, and J. Zhu, "Characterization of kerosene distribution around the ignition cavity in a scramjet combustor," Acta Astronautica, vol. 134, pp. 11-16, 2017.

[32] P. Manna, M. Dharavath, P. K. Sinha, and D. Chakraborty, "Optimization of a flight-worthy scramjet combustor through CFD," Aerospace Science and Technology, vol. 27, no. 1, pp. 138-146, 2013.

[33] Z. Zhong, Z. Wang, M. Sun, and H. Wang, "Combustion characteristics in a supersonic combustor with ethylene injection upstream of dual parallel cavities," Proceedings of the Institution of Mechanical Engineers-Part G: Journal of Aerospace Engineering, vol. 230, no. 13, pp. 2515-2522, 2016.

[34] D. Shi, W. Song, Y. Wang, and Y. Wang, "Effects of cavity configurations on flameholding and performances of kerosene fueled scramjet combustor," International Journal of Turbo and Jet Engines, vol. 34, no. 3, 2017.

[35] Ansys, ANSYS Fluent Theory Guide 15.0, ANSYS Inc., Canonsburg, PA, USA, 2013.

[36] Y. Yang, Z. Wang, M. Sun, H. Wang, and L. Li, "Numerical and experimental study on flame structure characteristics in a supersonic combustor with dual-cavity," Acta Astronautica, vol. 117, pp. 376-389, 2015.

[37] H. Wang, Z. Wang, M. Sun, and N. Qin, "Experimental and numerical investigation of cavity-based supersonic flow and 
combustion," Proceedings of the Institution of Mechanical Engineers-Part G: Journal of Aerospace Engineering, vol. 228, no. 5, pp. 781-798, 2014.

[38] H. Wang, Z. Wang, M. Sun, and N. Qin, "Combustion characteristics in a supersonic combustor with hydrogen injection upstream of cavity flameholder," Proceedings of the Combustion Institute, vol. 34, no. 2, pp. 2073-2082, 2013.

[39] H. Wang, Z. Wang, M. Sun, and N. Qin, "Large eddy simulation of a hydrogen-fueled scramjet combustor with dual cavity," Acta Astronautica, vol. 108, pp. 119-128, 2015.

[40] W. Huang, Z.-G. Wang, L. Yan, and W.-D. Liu, "Numerical validation and parametric investigation on the cold flow field of a typical cavity-based scramjet combustor," Acta Astronautica, vol. 80, pp. 132-140, 2012.

[41] J. Shin, K. H. Moon, and H.-G. Sung, "Numerical simulation of hydrogen combustion in model SCRAMJET combustor using IDDES framework," in Proceedings of the 20th AIAA International Space Planes and Hypersonic Systems and Technologies Conference, pp. 1-12, Glasgow, Scotland, July 2015.

[42] S. Zhang, J. Li, F. Qin, Z. Huang, and R. Xue, "Numerical investigation of combustion field of hypervelocity scramjet engine," Acta Astronautica, vol. 129, pp. 357-366, 2016.

[43] L. Jin, J. Lei, W. Huang, and Z.-G. Wang, "Numerical investigation on hydrogen combustion in a scramjet with $3 \mathrm{D}$ sidewall compression inlet," Acta Astronautica, vol. 105, no. 1, pp. 298-310, 2014.

[44] C. Liu, J. Tu, and G.-H. Yeoh, Computational Fluid Dynamics: A Practical Approach, Elsevier, Amsterdam, Netherlands, 2007.

[45] F. Alff, U. Brummund, W. Clauss, M. Oschwald, J. Sender, and W. Waidmann, "Experimental investigation of the combustion process in a supersonic combustion ramjet (SCRAMJET) combustion chamber," in Proceedings of the DGLR-Jahrestagung, pp. 629-638, Bremen, Germany, 1994.

[46] M. Oevermann, "Numerical investigation of turbulent hydrogen combustion in a SCRAMJET using flamelet modeling," Aerospace Science and Technology, vol. 4, no. 7, pp. 463-480, 2000.

[47] P. Gerlinger, P. Stoll, M. Kindler, F. Schneider, and M. Aigner, "Numerical investigation of mixing and combustion enhancement in supersonic combustors by strut induced streamwise vorticity," Aerospace Science and Technology, vol. 12, no. 2, pp. 159-168, 2008.

[48] R. Baurle, T. Mathur, M. Gruber, and K. Jackson, "A numerical and experimental investigation of a scramjet combustor for hypersonic missile applications," in Proceedings of the 34th AIAA/ASME/SAE/ASEE Joint Propulsion Conference and Exhibit, Cleveland, OH, USA, July 1998. 